\title{
The Effect of Leadership Styles on Project Implementation
}

\author{
Tamburo Michael Renzi \\ Department of Business Management, LIGS University, Honolulu, HI, USA \\ Email: mr.tamburo@gmail.com
}

How to cite this paper: Renzi, T. M. (2020). The Effect of Leadership Styles on Project Implementation. Open Journal of Leadership, 9, 198-213.

https://doi.org/10.4236/ojl.2020.94012

Received: October 7, 2020

Accepted: December 1, 2020

Published: December 4, 2020

Copyright (c) 2020 by author(s) and Scientific Research Publishing Inc. This work is licensed under the Creative Commons Attribution International License (CC BY 4.0).

http://creativecommons.org/licenses/by/4.0/

\begin{abstract}
The goal of all leadership styles in project implementation is to transform and lead the project to success. Transformative leadership styles utilize emotional intelligence to motivate team members in a project and create a psychologically safe environment which encourages better performances during project implementation. Leadership is important for inspiration, guidance, and defining the objectives of every project. The aim of this research is to evaluate the effects of leadership style on project implementation. Through content analysis qualitative research design utilizing secondary sources, there emerges a trait that defines good leadership and how it can be leveraged for proper outcomes in project implementation and management. The study concludes that project implementation includes the engagement of teams under one or multiple leaderships. Leaders have the responsibility of engaging with human resources more than any other resource in the organization. All the phases of project implementation are vital and must be managed with dexterity and exemplary leadership performance.
\end{abstract}

\section{Keywords}

Leadership, Ethics, Motivation, Transformation, Project Implementation, Psychological Safety, Emotional Intelligence

\section{Introduction}

\subsection{Background}

Leadership is the process of guiding others to complete a certain task. Leadership is a source of inspiration and guidance to members of a team. Democratic, autocratic, laissez-faire, bureaucratic, servant, and transactional leadership styles are all lauded as viable methods of guidance in which project implementation can utilize to varying degrees of success. The general consensus is that there is 
no standard style of "one-fits-all" in organizational leadership, and various styles may be conjured for desired results. However, despite this liberal approach, all styles of leadership must strive to meet one end: driving the organization towards meeting its visions and surpassing the goals defined while also maintaining ethicality and retaining the elements of motivation and enthusiasm that keeps the team members focused. The definition of the qualities of a good leader in varying environments may differ, but the general sentiments about what is expected of them remain similar. Leadership is a process of social influence in which a person enlists the aid of others in the accomplishment of a common task. Leadership, therefore, entails listening, inspiring, and empowering as well as providing the tools needed to support organization and individual visions.

\subsection{Defining Leadership}

Leadership, in general, is the act of providing guidance. It is generally defined as the process of social influence and the utilization of the efforts of other people to achieve a defined goal. This definition takes into account the social and corporate strategies, as well as the management aspects. However, various scholars have different perceptions of what constitutes leadership.

Kevin Kruse (2013), the CEO of Lead and an author of various books on leadership, states that leadership does not mean having titles, seniority, or the positioning in a social or corporate hierarchy. Being the highest earner or belonging with the executives, therefore, does not make one an automatic leader. Similarly, personal attributes, like being domineering, tall, boisterous, influential, or charismatic, do not translate to good leadership. Likewise, management and leading are different, and being a manager does not mean that one becomes a good leader. Having defined the common misconceptions about leadership, it is prudent to define what leadership means and why it is important for project management.

Leader is someone who has followers. This definition seems simple and likes a tautology, but in essence, it is the basis of leadership. Having followers is what makes the leader able to translate a vision into reality (Kruse, 2013). Bill Gates commented that leaders are those with the ability to empower others, while John Maxwell defined a leader as one with influence. In all definitions of leadership, there are elements that must be present. These include social influence and a goal that others must be empowered to achieve. In the context of project implementation, this definition is complete and thus will be applied to the different phases of project implementation.

Page et al. (2019) defines leadership as an art of finding elements that motivate a team and using these elements to define a path that the team may use for measurable progress, they state that the position of a leader should not, at any time, manifest autocratic characteristics but should leverage the advantages of democracy in leading the teams towards a common goal. They confirm that leadership is not about "re-inventing the wheel" of leading but should rely on borrowed elements that have recorded variable levels of success. In his definition, 
they summarize: "A leader inspires others to act while simultaneously directing the way that they act. They must be personable enough for others to follow their orders, and they must have the critical thinking skills to know the best way to use the resources at an organization's disposal" (Page et al., 2019). This summary point out to two aspects that are important in leadership: Are being "personable" meaning understanding the emotional inclinations of the followers, and "critical thinking" meaning that leaders must be intelligent.

The aspect of intelligence and being personable is elaborated by Professor Clawson (2001) in his study titled A Leader's Guide to Why People behave the way they $D o$. In this article, Clawson analyzes the concepts of leadership, drawing from the generic teachings about effective leadership and assimilating these styles in a psychoanalytic approach, arguing for emotional intelligence as an important element in defining effective and defective leadership. According to Clawson, leadership is important due to one fundamental course: the desire to achieve. However, the faults human psyche as an impediment to achieving much by the leaders who fail to place the interest and emotional state of others in their leadership. Clawson states that his assertions may be confused by inferring that leaders become adept in psychology and become more involved with the emotional states of their followers instead of being leaders. However, he asserts that the call to understand why people in groups behave as they do is the key to unlocking the potential of any team, and thus fulfilling the goal of leadership, and that is, achieving by inspiring change.

\subsection{Leadership in the Phases of Project Implementation}

\section{Project Implementation}

Project implementation is the transformation of ideas from their abstract form in the proposals to a realistic presentation while keeping the objectives at higher interest and utilizing the available resources (material, human, and time) for quality output. There are four phases of project implementation: the initiation phase, which included the analysis of the work plan; the planning phase, which considers the resources available against the stringent deadlines and objectives; the implementation phase, which is the actualization of the ideas in the paper; and the closing phase, which evaluates the output against the input and defines the successes, the challenges and the means of improving the project in the future. It is given that leadership is vital in all these phases and plays a significant role in the transition from one phase to another. It is thus impossible to separate any phase of project implementation with leadership.

Project implementation utilizes leadership at varying degrees. The initiation phase is the starting phase. This level requires in-depth leadership involvement since the scope of the project must be defined, as well as the allocation of duties and resources. The planning phase includes developing a roadmap that the team will follow. There are various suggestions for developing an effective roadmap. These include the SMART (specific, measurable, attainable, realistic, and timely) approach and CLEAR (collaborative, limited, appreciable, and refine-able) ap- 
proaches. Whichever course a leader selects, they are responsible for defining the path that the project should follow. The third phase is the project execution phase. At this stage, minimal direct engagement of leadership is mandated. However, the teams must be well defined, the resources assigned, all procurements made, and a schedule set. The leader must thence trust the team to implement the project with the instructions that have been provided.

\subsection{Objectives of the Study}

This research seeks to analyze the role that leadership plays in each stage of project implementation and the value it adds. The research will dwell on the themes of organizational leadership, motivation, and the transformational power of different styles of leadership. The paper will conclude that ethical and transformative leadership is vital in project implantation and serves as an epoxy that drives the teams towards achieving the objectives of any project. The goal of all leadership styles in project implementation is to transform and lead the project to success. Transformative leadership styles utilize emotional intelligence to motivate team members in a project and create a psychologically safe environment that encourages better performances during all the phases of project implementation. The key performance indicators like objectivity, quality of the deliverables, and general performance against time, must be considered. The last phase is the project closure. The leadership involvement at this phase must be well defined. The leaders must account for the progress of the team and mark them against a punch-list.

\subsection{Research Tasks/Methodology}

The paper will utilize secondary data analysis methodology. In this research, archival information from credible websites, business and leadership journals, reports, and peer-reviewed literature will be utilized. The sources of these data will be from academic databases of research organizations, public records, and government agencies. Relevant sources will be incorporated if and only if they are from credible authors and by credible organizations or institutions.

\subsection{Hypothesis}

The study hypothesizes that a transformative leadership style can utilize specific traits to have a greater impact during project implementation. There are various factors that are important elements of employee motivation during project implementation. Leaders have to motivate the employees so that their performance can remain high for the benefit of the project. The analysis of relevant literature is expected to confirm or dispute this hypothesis.

\subsection{Theoretical Background}

An extensive search of the literature was performed from various databases using various key terms, including "leadership", "psychological safety", "positive 
psychology", "job insecurity", "job satisfaction", and "project implementation". The articles ranged from the years 2004 to 2020 . The sources selected were all relevant to the study.

\section{Literature Review}

According to (Sarver \& Miller, 2014), leadership is about responsibility and proper management of the human and material resources to bring change and enable progress. Transformational leadership is essential for all leaders who have the vision to inspire change. Leaders in all faculties, including business, law enforcement agencies, political scopes, and managerial positions, are responsible for pushing change by inspiring cooperation among team members. Change is witnessed through improved job performance, cohesion among team members, and morale for motivation for the execution of duties. Leadership styles vary, and the amount of involvement with the team activities also differ. However, irrespective of the leadership style that a leader explicates, they must be guided by the personality traits of neurotics, extraversion, openness, conscientiousness, and agreeableness. There are no best transformational leadership skills as each skill has its merits and levels of success in different situations.

Sarver and Miller (2014) also assert that managers must utilize communication, consultations, and consideration of personal opinions of team members before decision making. Nurturing transparency and creating an aura of trust in a project is the first step in having a cohesive team where psychological safety thrives, and everyone is free to share their opinions. The collective consultations and consideration of personal opinions are important in project implementation because different team members have varied perspectives gathered from varied experiences, which in collection form an important source of information from which other officers and also the managers can learn. All phases of project implementation are dynamic, and a set of standards of leadership cannot effectively address the various scenarios (Singh et al., 2013). It is, therefore, important that managers encourage their team members to share experiences, adapt to self-discipline, set a clear boundary between personal biases and execution of duties, and make decisions based on logic and respect for the law.

According to Edmondson et al. (2016), project implementation thrives where there is a harmonious integration between the leadership style and the objectives of the project. In this environment, psychological safety thrives, and the freedom that this brings enables the team members to employ their talents without fear of retribution, which drives different phases of the project to different rates of success. Psychological safety is the extent to which people perceive their environment as a conducive place to exercise risky interpersonal behaviors such as seeking help, speaking for or against something, and find new methods of learning.

The limited evaluation of the positive impacts of psychological safety by Cao and Zhang (2020), in the general context, shows that its benefits traverse enhanced 
emotional commitment at in team projects, encourages sharing of expertise, and this translates to better individual performance. These assertions show that psychological safety is beneficial at the personal, interpersonal, and professional levels. Edmondson et al. (2016) agree with Cao and Zhang (2020) that psychological safety utilizes personal level characteristics and, in turn, influences how people engage in their works. Psychological safety is anchored on the relational development systems metatheory, which states that the interaction between individuals and their inner-selves, and between the individuals and their environment, is the basis for human development. Psychological safety has the potential of transforming the individuals at the personal level and at the contextual level. Hence, there is a person-context situation that serves to fuel one's self in relation to the environment and with each other as shown in Figure 1.
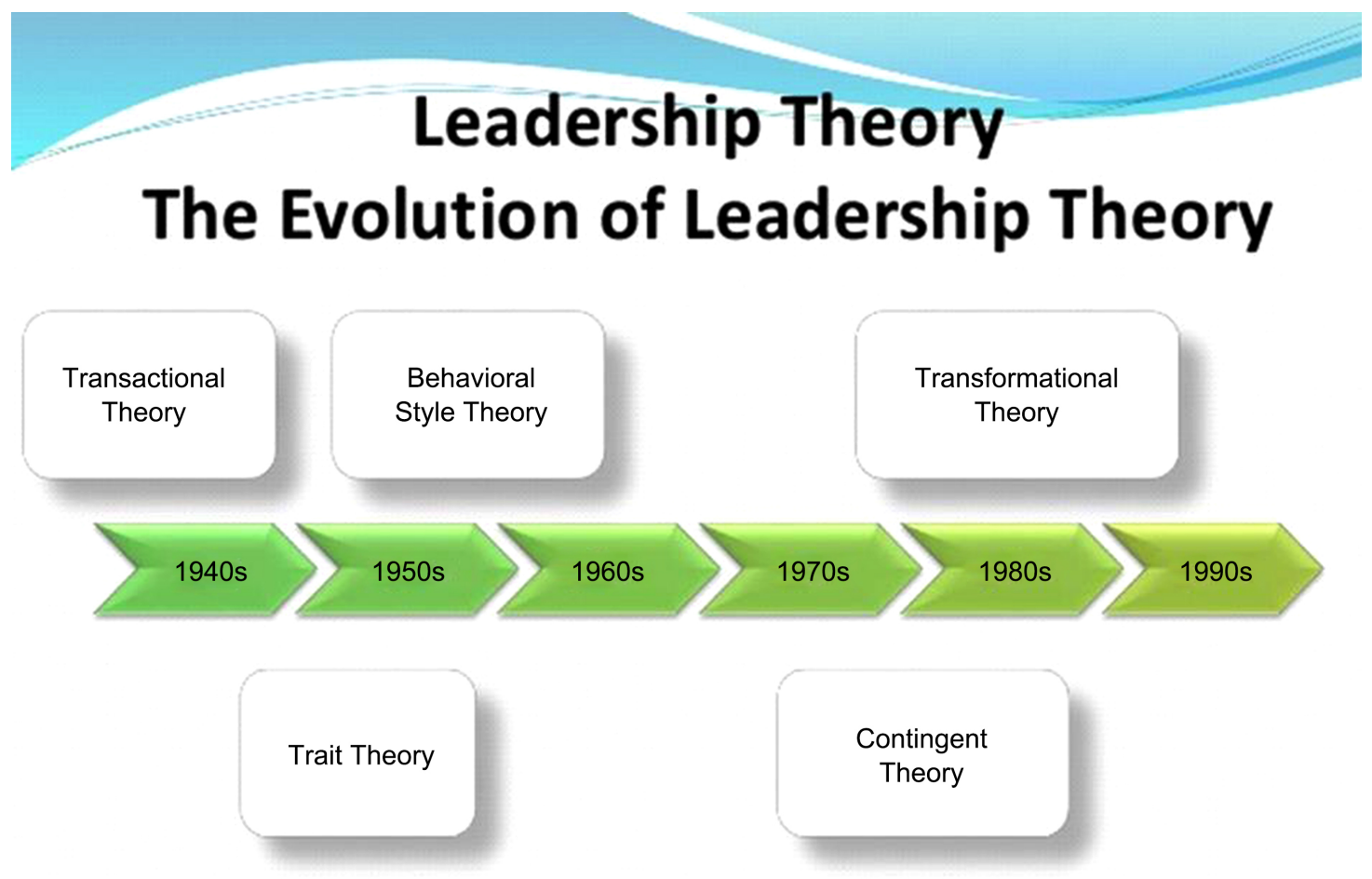

Figure 1. The evolution of leadership. Adopted from Yaakob, H. (2014, September 24). Leadership Style-Case of Sony Ericsson [Image] https://www.slideshare.net/sham_260175/leadership-ssony-ericsson. Notes. The Figure has been utilized to demonstrate the leadership theory and its evolution. The data from this table are well explained by David A. Van Seters and Richard H.G. Field, 1990 in their journal article The Evolution of Leadership Theory. In this article, Seters and Field argue that leadership theory has evolved from a one-dimensional aspect that focuses on "internal" and "individualistic" processes to a multidimensional aspect that gives considerations to the opinions of the majority. They trace the eras of leadership, from the Personality Era. In this era, they show the beginning of an understanding of theories of leadership theories, including the Great Man Period and the Trait Period. In this era, men and women who copied the traits of great leaders were assured of similar results. They then follow the Influence Era. In this era, the relationship between leaders and followers was established. Leadership became a way of influencing others and not nature versus nurture element. The Behavior Era followed, and in this era, leadership was stated to be comprised of a subset of human behavior. As such, leaders and managers started seeking an education that modified their behaviors to conform to scholarly advice on effective leadership and management. The Situation Era followed, and this era asserted that leaders emerged from environmental influences and social statuses. From then, other eras followed, including the Contingency Era, the Transactional Era, the Anti-Leadership Era, the Culture Era, and finally, the Transformational Era. All these eras were accompanied by theoretical perspectives, each defining the best elements of leadership (Seters \& Field, 1990) revised in 2014, University of Alberta, Canada. 
The universal definition of psychological safety does not mean that it is static in its application. Project implementation teams are composed of workgroups that interact at various capacities, thus having diverse implications on an individual's learning and development (Edmondson et al., 2016). For instance, a company specializing in production will have different workgroups (peer-to-peer relations), such as friendships within the production department and also in the assembly department. Similarly, in the healthcare setting, the workgroups will differ, depending on the area of specialty. Nevertheless, the characteristics of all workgroups are determined by the nature of the project, and there is a universal agreement on adherence to professional norms and organizational mandates. The nature of the project and the style of leadership may, therefore, encourage psychological safety, based on the composition of its workgroups, or it may otherwise frustrate such relationships.

According to Clawson, (2010) effective leadership is pegged on the understanding of the emotional aspects of human beings. He acknowledges that human beings are different, yet there are factors fundamental to our being that should be understood by others around us if they seek to understand our behaviors. Clawson argues for nature and nurture, claiming that nature has been proven to provide the blueprint for "not only physical characteristics like eye and hair color, metabolism and body shape but also biochemical balances and emotional tendencies as well as more fundamental species-specific instincts or drives like breathing, eating and drinking, reproducing and socializing" (p. 5). In this quote, Clawson summarizes the basic elements of human existence and their relationship with others. Arguing in favor of nature, Clawson states that our genetic endowment, like the physical characteristics, is unchangeable, permanent, and definitive of who we are. He also asserts that the bio-chemical inheritances like how we metabolize, mature, react, and perceive things are embedded in our DNA. Furthermore, biological functions such as socializing, he asserts, are predefined in our genetic codes. This argument for nature is an inference that the aspects of our existence that are imprinted in our systems cannot be modified. However, Clawson provides a relief, asserting that we are not bound to be slaves of these characteristics, as aspects that define our socialization can be trained.

The above analysis by Clawson provides a basis for understanding why leaders should be physiologically apt. It is true that there are aspects of people's childhoods that are difficult to change, and this determines how they perceive life and interact with groups. It is difficult to rewrite these things on people, but understanding their causes and how they manifest is important in understanding the individual and designing suitable ways of approaching them as a leader (Rabbanee et al., 2019). In this respect, Clawson gives a simple case study in which a mother who grew up without enjoying the comfort of approval from her parents finds herself unable to notice the milestones achieved by her daughter. As such, she uses her daughter to channel her childhood "holes" and, in effect, focusing their conversations towards appreciating her achievements. The overall effect is 
that she is hurting her daughter, who also desires her approval. Clawson advises that the failure of either party to understand these factors may lead to the perpetuation of the "hole" and affect the people that surround them. This analysis shows that apart from emotional intelligence, leaders should learn the background of their followers and understand how the events of their lives may have influenced their current personalities. Leaders should understand how to read emotional cues and the best ways to navigate through them so that they leverage from them or redirect these aspects of personality towards productivity.

Page et al. (2019) highlight that leadership is about learning how to manage people, both from technical perspectives and emotional tenets. Research shows that emotionally intelligent leaders are better decision-makers and create emotional safety at the workplace than those who neglect developing tactics in reading emotional cues. Page agrees with Clawson and explains the memetic factor, the ideas and beliefs that people acquire and develop, then reproduce and pass. He asserts that memes are the building blocks of the mental faculties and are, therefore, a complement to the genetic, physical building. Ideas are therefore conceived, executed, and then passed through successively to the next generations. Clawson supports this idea and identifies three kinds of memes, "memes of distinction, strategy, and association" (p. 8). However, he notes that despite the importance of memetic factors, those who fail to transcend their natural inclinations, or the memetic predispositions, fail to make meaningful impacts in the advancement of their lives as leaders. The other highlight is the effects of our values, assumptions, beliefs, and expectations on our existence. According to Clawson, everyone is subject to values, assumptions, beliefs, and expectations (VABEs), and they define how one perceives leadership and life.

Pinckney (2015) also highlights the importance of emotional intelligence in defining leadership. Clawson argues that leaders are made, or rather; they make themselves through learning and continual development. Effective leaders understand the VABEs of others and work to influence them towards positivity. The epitome of leadership is therefore not measured on how the individual leader achieves, but on the extent that they impact others towards self-development (Page et al., 2019). Leaders are, therefore, change-makers, leading through example and influence.

\section{Theoretical Basis: Leadership and Project Implementation}

\subsection{Transformational Leadership and Motivation of Project Members}

Motivation is the psychological drive to work towards achieving a certain goal. Motivation gives purpose and direction. Ozcelik (2004) defines motivation as a willingness to exert high levels of effort so that organizational goals can be achieved. Pinckney M.Y. (2015) asserts that motivation is the root of drive for all employees, and the presence or lack of it translates to consequences that affect 
the organization in variable depths. Motivation is a psychological aspect, and therefore, understanding the factors that encourage action (why people do what they do) is a major step towards understanding how to improve the work environment. Motivated individuals view project duties as an extension of their personal projects, and through their efforts, the productivity of the organization is improved, and the competitive advantage of the organization rises. The general characteristics of self-driven employees are more involving in engagements, high problem-solving skills, a better relationship with their workmates and, by extension, the employer and other paraprofessional colleagues, innovativeness, creativity, and more focused to meet the clientele needs.

Motivation is directly related to job satisfaction. Subhakaran and Dyaram (2018) state that psychological safety creates an environment that employees are free to exercise their discretion, and thus they can speak up for or against issues that affect them. The satisfaction that is derived from that freedom results in a motivated workforce. They also emphasize that poor cultures like discouraging free expression lead to a demotivated team member. The workforce thence shrinks at their opinions in fear of being victimized, viewed as critical, and self-serving, and thus, there is a poor relationship between such people and the team leader. As a psychological aspect, motivation can, therefore, be increased or frustrated through poor leadership practices. For example, unethical and dictatorial leadership, poor communication structures, poor relationships in team works, a stressful working environment, and other factors can contribute to the workers having a poor attitude towards work. Similarly, a better interpersonal relationship, ethical leadership, a work environment that encourages freedom of expression, and encourages experimentation of ideas nurtures positivism, psychological safety, and the resultant workforce is greatly motivated.

\subsection{Transformational Leadership, Emotional Intelligence, and Project Implementation}

Ozcelik (2004) states that, there is a strong relationship between the emotional fit and good leadership that inspires expression. The more congruence the emotional fit is with the emotional environment, the safer an individual fits within the team. Emotional intelligence is the ability of one to recognize their emotions and that of others and manage them effectively. It involves mastering three basic skills: being able to identify one's emotions, the ability to use those emotions to one's advantage, and the ability to regulate one's emotions as well as those of others.

Emotional intelligence largely involves adopting and building suitable interpersonal skills. It is instrumental in defining leadership. Zhou and Zhu et al. (2020) state that emotionally intelligent leaders are aware of their emotions can harness them and apply them in daily tasks like problem-solving and managing people in social and/or professional settings. Emotional intelligence is measured and expressed as emotional quotient (EQ). 
The EQ measurement is not scientifically validated as a psychometric measure; however, its values are used to define leadership qualities, performance in jobs, and other interpersonal relational aspects. There is a connection between emotional intelligence and decision making which is beneficial to leadership. The composition of a team requires affirmativeness, assertiveness, and strong anchorage on ideals as defined by the project's objectives (Zhou, Zhu et al., 2020). The more emotionally intelligent the leader is, the more they are able to create a psychologically safe environment for their team members. Therefore, emotional intelligence can be manipulated by leaders to nudge others to serve the project's needs. The lack of scientific validation makes emotional intelligence an abstract science; nevertheless, sociological opinions point that being emotionally intelligent, or lack of it, are important in defining the relationships between individuals and in building social cohesion.

The major focus on emotional intelligence is that it enables one to read emotional cues from those they relate with and solve interpersonal and personal problems, thus contributing to the emotional and physical health of themselves and others too. Emotional intelligence enables corporate leaders to read and interpret positive and negative emotional signals from others' body language, vocal, and facial expressions (Zhou, Zhu et al., 2020). Emotional awareness thus enables one to be conscious of the positive and negative emotional states of others and themselves. The ability to identify one's emotions at a glance of their posture and body language enables one to discern better ways to relate to them at personal levels irrespective of the existing relationship. In a professional setting, a supervisor who can read the emotional state of their team strikes out as relatable and understanding. Negative emotional signals like sadness and frustrations reduce the performance of workers and close up individuals' personal spaces from access to the people they do not feel overly comfortable with. Being emotionally aware thus enables an individual to breach the personal barriers of others' emotional fences and be able to offer solace or recommend better ways of finding help to those individuals.

Kim and Kim (2020) define psychological safety in terms of emotional awareness of the emotional environment within the workplace. They infer that business leaders can foster good relationships with others due to their ability to understand the emotional chords of other persons and connect with them empathically. The majority of social activities include active listening to other people's verbal communications, watching their behaviors, and discerning the superficial and profound meanings of their messages, and responding appropriately. For instance, an emotionally stressed employee will show restlessness, lack of composure, emotional closure, and will avoid opening up to individuals they are not emotionally close to. Similarly, excited persons will show general excitement, openness, and warmth in their facial and verbal communications.

Hans \& Gupta (2018) assert that emotional interconnectedness is the strength of a team as it supports collaboration, and the result is positive team attitudes 
and improved performance. Emotional intelligence, therefore, leads to increased job performance and healthy professional relationships (Hans \& Gupta, 2018). Leaders show great tendencies to harness and manage their emotions; thus, they are more inclined to respond to various situations with logical reasoning rather than emotions. Logical reasoning enables one to disconnect their personal lives from professional relationships. The disconnection between the personal and professional lives enables individuals to affect their professional duties like effective communications and team management, which creates a calm environment suitable for job performance. The ability to manage stress, builds relationships, inspires, and motivates individuals as well as one's self has a positive impact on professional commitments. Similarly, Page et al. (2019) posit that by affecting the emotional, cognitive aspects of an employee, it leads to emotional strains that lower activity and, subsequently, performance. Emotionally intelligent employees can derive satisfaction from their professional duties, respond to stress positively, and involve logic in discussing discontentment rather than using emotional outbursts.

\section{Analysis of Findings}

\subsection{Analysis}

The above analysis has shown that there are specific behavioral traits that distinguish between successful leaders and ineffective leaders. Project implementation requires team cooperation at all phases of its implementation. As such, a team must be cohesive, and the team leader must show competency in balancing between personal and professional attachment. Professionalism is admirable, but the leader must be able to connect with the team members at personal levels whilst also maintaining a professional distance. Infringing into personal spaces is also undesirable as the leader might find them deeply engorged in the personal lives of the team members. The key is, therefore, finding a perfect balance that uses emotional intelligence and motivation to harness the power of team members to accomplish the projects' goals.

Leadership is the epoxy that holds a team together and guides it towards the achievement of its set goals. Ethical leadership should utilize strategies that encourage free expression, especially in decision making. Girdwichai and Sriviboon (2020) state that the best project implementation strategies should be developed with consideration of the social needs of the workforce. Environment and training, as well as organizational strategies to meet these demands, matter to a great extent. As evident, sometimes the line between work and life is complex and demanding, and sometimes the boundaries between professional life and personal needs may clash, leading to a work-life balance crisis (Edmondson, 2019). However, this deficiency can be off-set by having a good strategy that allows employees to have a safe environment for the expression of certain frustrations. Thus, the goals that the leadership set during the project implementation must be attainable. 
Ethical leadership's role in creating a psychologically secure environment is developing interpersonal skills. Edmondson (2019) asserts that effective and transparent communication is the foundation of proper and ethical leadership as it builds trust and encourages others to communicate in return. Effective communication is the recipe for success in creating effective and meaningful contact with the employees. For example, the most important aspect of communication leaders is clarity. Being simple and clear makes it easier for clients to understand the communiqué and removes the need to repeat oneself. Secondly, the leader must be transparent in defining the scope of their obligations. This means admitting that as a leader, there are limits, boundaries, and restrictions that guide leadership.

The findings also confirm that transformational leadership is effective only to the extent that it inspires transparency in the team set-up. Yin et al. (2019) discuss transformational leadership and how sharing and transparency in communication are important in creating psychological safety. Both Yin et al. (2019) and Edmondson (2019) agree that interpersonal communication is enhanced through active listening. Active listening means paying attention to the verbal and non-verbal cues of the employees so that what the employees say becomes an asset that can be used to reflect upon their needs and understand them better. Active listening also creates trust, and the employees will be open and be confident to talk to the leader. The assurance that one is being understood and listened to is therapeutic in itself. Therefore, in any practice setting, in addition to speaking clearly, for effective communication, the ethical leader hoping to enhance team performance during project implementation must be a listener too.

\subsection{Discussions}

The basis of this study has been to analyze whether a transformative leadership style can utilize specific traits to have a greater impact during project implementation. Findings from various literatures have thus confirmed the hypothesis by establishing that traits such as emotional intelligence and motivational theories can be utilized to create a psychologically safe environment that encourages team performance. The general findings confirm that there is a correlation between psychological safety and motivation at job performance. The above analysis also shows an established relationship between psychological safety and emotional intelligence, motivation, ethical leadership, and the environmental circumstances at the workplace (Anonymous, 2019). It is also clear that leadership has the responsibility to perpetuate an understanding and healthy interpersonal relationship at the workplace through democratic leadership and not fear through autocracy. Fear has a paralyzing effect in a dictatorial relationship of unequal parties and peers who feel that their esteem is low, majorly due to demotivating circumstances at work, home, or school. The focus of developing healthy interpersonal relationships is to rid-off the fear (Ahmad \& Umrani, 2019). This is the basis of the concept of psychological safety. 
Different leadership styles auger different results, and in this respect, these leadership styles affect team cohesion during project implementation differently. However, this discussion has singled out transformational leadership as leadership that utilizes democratic principles while also engaging the other leadership styles in varying proportions for different successes at the project implementation level (Weber \& Avey, 2019). In the analysis, it is a consensus among the scholars that psychological safety in the workplace is employees' ability to act with freedom without regard to the negative consequences that arise from their activities, appearance, status at work, or their career in general. Psychological safety develops in four stages: The Inclusion, Learning, Contribution, and Challenge Safety stages (Clark, 2020). It is nurtured by the relationship between employees at an organization. As such, psychological safety is the major ingredient that sets the stage for a successful implementation of goals directed at achieving project goals. Transformational leadership is characterized by affirmative decision-making, methodical inspiration, and effective communication to inspire teamwork, cohesion, and improved performance to spearhead change and achievement of goals (Erkutlu \& Chafra, 2019). These skills inspired by transformational leadership are vital for the realization of change. Therefore, through communication and cooperation, measurable change can be realized as shown in Figure 2.

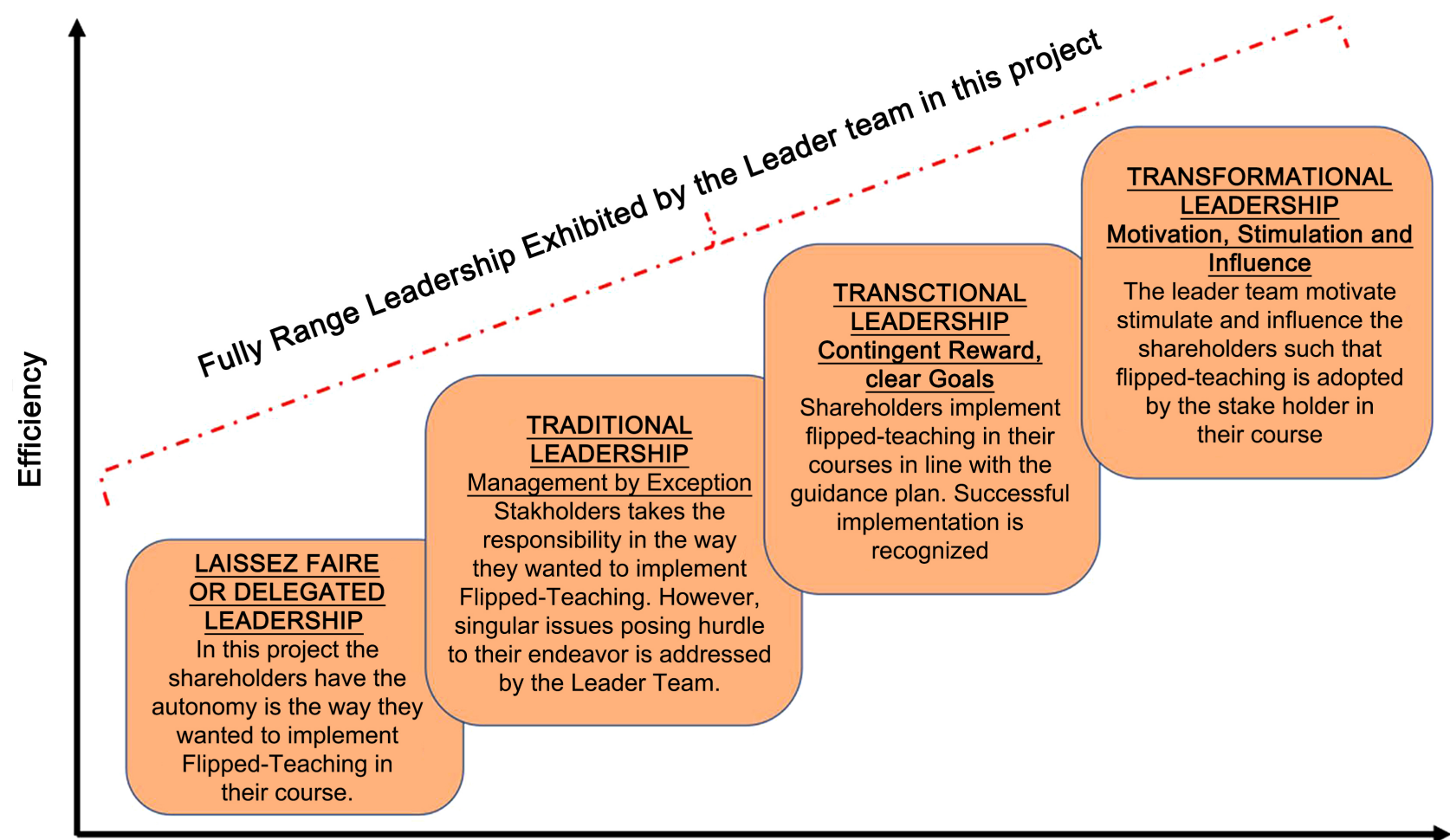

\section{Engagement (Active $\rightarrow$ Passive)}

Figure 2. Leadership efficiency and efficiency. BMC Medical Education. From:

https://bmcmededuc.biomedcentral.com/articles/10.1186/s12909-019-1896-0. Note: The Figure represents a leadership model showing a leadership team role that should be used to implement transformations that have utilized Mento's change adopted from Banerjee, Y., Tuffnell, C Alkhadragy, R. (n.d.). Leader Team [Image]. 


\section{Conclusion}

In summary, project implementation takes into account the engagement of teams under one or multiple leaderships. Leaders have the responsibility of engaging with human resources more than any other resource in the organization. All the phases of project implementation are vital and must be managed with dexterity and exemplary leadership performance. The different styles of leadership have different advantages that they offer to the project. An autonomous team may benefit from a laissez-faire system with minimal involvement with the team's intricate details. A rigid and hard to control team may require autocratic assertions to get it in control, but this must be exercised with caution since it instills fear and discourages leadership-follower interactions, which is good for the team's success. The overall system narrows down to transformational leadership. The leader must ensure that the team is continually self-developing and improving. Project implementation requires an upward trend that favors an inclination towards meeting the set goals.

On project implementation, creating an environment of safety is important in allowing the development of employees. It is important that leaders allow employees autonomy. Autonomy is important as it gives the employees a sense of self-determination, independence, and awards control. Secondly, leadership has a great influence on defining the success of a team. Democratic leadership, in particular, is fluid and allows the holistic development of an individual. In essence, Clawson compares control theory and choice theory and concludes that the choice theory, inherent in democratic leadership, provides a solid foundation for developing leadership roles, attitudes, and direction. The choice theory also allows the autonomy required to inspire self-development. The call to understand why people in groups behave as they do is the key to unlocking the potential of any team, and thus fulfilling the goal of leadership, and that is, achieving by inspiring change.

\section{Conflicts of Interest}

The author declares no conflicts of interest regarding the publication of this paper.

\section{References}

Ahmad, \& Umrani (2019). How an Ethical Leadership Style Impacts the Elusive Job Satisfaction Quest. Human Resource Management International Digest, 28, 36-37. https://doi.org/10.1108/HRMID-10-2019-0234

Anonymous Author (2019). How an Ethical Leadership Style Impacts the Elusive Job Satisfaction Quest: Exploring the Influence of Psychological Safety and Green HRM. Human Resource Management International Digest, 28, 36-37. https://doi.org/10.1108/HRMID-10-2019-0234

Banerjee, Y., Tuffnell, C., \& Alkhadragy, R. (n.d.). Leader Team [Image]. BMC Medical Education.

https://bmcmededuc.biomedcentral.com/articles/10.1186/s12909-019-1896-0 
Cao, F., \& Zhang, H. (2020). Workplace Friendship, Psychological Safety, and Innovative Behavior in China: A Moderated-Mediation Model. Chinese Management Studies, 14, 661-676. https://doi.org/10.1108/CMS-09-2019-0334

Clark, T. (2020). The 4 Stages of Psychological Safety. Oakland: Berret-Koehler Publishers, Inc.

Clawson, J. (2001). A Leader's Guide to Why People Behave the Way They Do.

Cyert, R. (1990). Defining Leadership and Explicating the Process. Nonprofit Management and Leadership, 1, 29-38. https://doi.org/10.1002/nml.4130010105

Edmondson, A. (2019). The Role of Psychological Safety. Leader to Leader, 2019, 13-19. https://doi.org/10.1002/lt1.20419

Edmondson, A. C., Higgins, M., Singer, S., \& Weiner, J. (2016). Understanding Psychological Safety in Health Care and Education Organizations: A Comparative Perspective. Research in Human Development, 13, 65-83. https://doi.org/10.1080/15427609.2016.1141280

Email Experience Council (2014). New EEC Leadership Announced [Image]. Email Experience. https://emailexperience.org/2016/07/new-eec-leadership-announced

Erkutlu, H., \& Chafra, J. (2019). Leader Psychopathy and Organizational Deviance: The Mediating Role of Psychological Safety and the Moderating Role of Moral Disengagement. International Journal of Workplace Health Management, 12, 197-213. https://doi.org/10.1108/IJWHM-12-2018-0154

Girdwichai, L., \& Sriviboon, C. (2020). Employee Motivation and Performance: Do the Work Environment and the Training Matter? Journal of Security and Sustainability Issues, 9, 42-54. https://doi.org/10.9770/jssi.2020.9.J(4)

Hans, S., \& Gupta, R. (2018). Job Characteristics Affect Shared Leadership: The Moderating Effect of Psychological Safety and Perceived Self-Efficacy. Leadership \& Organization Development Journal, 39, 730-744. https://doi.org/10.1108/LODJ-03-2018-0101

Kim, M., \& Kim, B. (2020). Analysis of the Importance of Job Insecurity, Psychological Safety, and Job Satisfaction in the CSR-Performance Link. Sustainability, 12, 3514. https://doi.org/10.3390/su12093514

Kruse, K. (2013). What Is Leadership? https://www.forbes.com/sites/kevinkruse/2013/04/09/what-is-leadership/?sh=39595411 $\underline{5 b 90}$

Kruse, K. (2019). Leadership and Development Program. https://www.kevinkruse.com/leadership-development-programs/

Ozcelik, H. (2004). Emotional Fit in the Workplace: Its Psychological and Behavioral Outcomes (Order No. NQ93163). https://search.proquest.com/docview/305055238? accountid=35812

Page, L., Boysen, S., \& Arya, T. (2019). Creating a Culture That Thrives Fostering Respect, Trust, and Psychological Safety in the Workplace. Organization Development Review, 11, 714-714. https://doi.org/10.12968/bjom.2003.11.12.11861

Pinckney, M. Y. (2015). Increasing Civility in the Workplace. JOCEPS: The Journal of Chi Eta Phi Sorority, 59, 11-16.

Rabbanee, F., Haque, M., Banik, S., \& Islam, M. (2019). Managing Engagement in an Emerging Economy Service. Journal of Service Theory and Practice, 29, 610-638. https://doi.org/10.1108/JSTP-12-2018-0276

Sarver, M. B. and Miller, H. (2014). Police Chief Leadership: Styles and Effectiveness. Policing: An International Journal of Police strategies and Management, 37, 126-143. https://doi.org/10.1108/PIJPSM-03-2013-0028 
Singh, B., Winkel, D. E., \& Selvarajan, T. T. (2013). Managing Diversity at Work: Does Psychological Safety Hold the Key to Racial Differences in Employee Performance? Journal of Occupational \& Organizational Psychology, 86, 242-263. https://doi.org/10.1111/joop.12015

Subhakaran, S., \& Dyaram, L. (2018). Interpersonal Antecedents to Upward Employee Voice: The Mediating Role of Psychological Safety. International Journal of Productivity And Performance Management, 67, 1510-1525.

https://doi.org/10.1108/IJPPM-10-2017-0276

Van Seters, D., \& Field, R. (1990). The Evolution of Leadership Theory. Journal of Organizational Change Management, 3, 29-45. https://doi.org/10.1108/09534819010142139

Weber, T., \& Avey, J. (2019). Speaking Up When Values Are Aligned. Baltic Journal of Management, 14, 578-596. https://doi.org/10.1108/BJM-10-2018-0345

Yaakob, H. (2014). Leadership Style-Case of Sony Ericsson [Image]. Slideshare. https://www.slideshare.net/sham_260175/leadership-ssony-ericsson

Yin, J., Ma, Z., Jia, M., \& Liao, G. (2019). Transformational Leadership and Employee Knowledge Sharing: Explore the Mediating Roles of Psychological Safety and Team Efficacy. Journal of Knowledge Management, 24, 150-171. https://doi.org/10.1108/JKM-12-2018-0776

Zhou, W., Zhu, Z., \& Vredenburgh, D. (2020). Emotional Intelligence, Psychological Safety, and Team Decision Making. Team Performance Management, 26, 123-141. https://doi.org/10.1108/TPM-10-2019-0105 